\title{
TEMPOS DE ALFABETIZAR: AS ESCOLAS RURAIS DE FEIRA DE SANTANA 1955-1963.
}

\section{$\underline{\text { Juliana Mangabeira Ribeiro }}$}

Bolsista FAPESB, Graduanda em História, Universidade Estadual de Feira de Santana, jullymangabeira@hotmail.com.

Orientadora Ione Celeste Jesus de Sousa, Departamento de Ciências Humanas e Filosofia, Universidade Estadual de Feira de Santana, ionecjs@gmail.com.

Participante do grupo de pesquisa, Histórias da Educação: Formação e trabalho docente, Infâncias e Culturas Escolares, Universidade Estadual de Feira de Santana.

PALAVRAS-CHAVE: Escolas Rurais; Professoras; Feira de Santana.

\section{INTRODUÇÃO}

O surgimento da cidade feirense pode ser considerado de cunho rural, pois da sesmaria pertencente a família Guedes de Brito e outra grande família a Peixoto Viegas, e com o decorrer do tempo o Arraial de Sant' Ana, onde se localizava a fazenda Sant'Ana dos Olhos d'Água, foi onde se iniciou a próspera cidade de Feira de Santana. Trazer esta discussão é perceber como o município que teve em suas origens questões rurais, lidou com a criação de escolas com teor rural.O seu desenvolvimento, principalmente por se encontrar em uma posição geográfica favorável (SANTOS, 2008), fez Feira de Santana trazer uma dualidade em seu crescimento, pois a cidade, que teve origem rural, sofria um processo de transformação das suas tradições conservadoras para um plano de urbanidade modernizadora, sob o cunho do progresso.

Na década em foco, 1950, a cidade novamente se expandia em vários equipamentos urbanos, dentre estes a criação de novas escolas, incluindo um projeto de escolas na zona rural. Anteriormente fora instalada na década de 1920(1927) a Escola Normal com o intuito objetivo de formar professoras/es para "espalharem seu saber pelo interior"( CRUZ e SOUSA:2012) . A destacar que entre 1935/1948 a escola normal feirense atuou como escola normal rural, sob a denominação de Escola Normal Rural da Feira de Santana (SOUSA:1999/2001) . Com este retorno da importância de escolas rurais na década de 1950, a zona rural não ficou fora dos projetos de desenvolvimento educacional em voga. A pesquisa visa investigar as escolas rurais instaladas em Feira de Santana: sua localização, quais professores/as atuaram nelas e sua relação com alianças políticas. As fontes evidenciaram que em sua grande maioria as escolas rurais localizadas no município eram unidocentes, com aulas ministradas apenas por uma professora, que deveria lecionar para diversas séries em um único local.

Feira de Santana, assim como outras cidades entre as décadas de 1950-1960, tiveram em suas zonas rurais a abertura de escolas rurais para alfabetizar as crianças residentes nas localidades. Em Feira de Santana foram diversos os distritos que tiveram um local designado para alocação da sala de aula, tal lugar em sua grande maioria era nas fazendas, onde a prefeitura denominava escola municipal localizada em determinada fazenda. Diversas portarias encontradas no jornal Folha do Norte, ressaltavam que $o$ prefeito preocupado com a quantidade de crianças em determinada localidade sem estudo, resolve abrir a escola para alfabetizá-las. Porém, as fontes indicam no propósito de escolas rurais as questões políticas envolvidas, pois algumas destas 
escolas foram instaladas em áreas de influência de vereadores, apontando que o jogo de interesses para abertura das escolas poderia determinar sua localização.

A discussão sobre política na história da educação é uma relação constante. Veiga (2008), afirma que desde a constituição de 1824 práticas políticas já estavam inseridas na educação, que em quase toda as instâncias sociais as questões referente a política esta envolvida, e na educação esta prática também é constante. .

Entre 1935 e 1941, em Feira de Santana até 1948, preparar professoras para lecionar nas escolas rurais era idealmente uma responsabilidade das Escolas Normais Rurais. Nelas as professorandas se formavam para atuar especificamente na zona rural. Em Feira de Santana, a Escola Normal em 1935 passou a se chamar de Escola Normal Rural, com o principal propósito de formar professoras para atuarem nestas escolas rurais (SOUSA, 1999). Foram criadas disciplinas que ensinavam "afazeres do campo" para as normalistas como maneira das mesmas aperfeiçoarem essas atividades. Mas além das Escolas Normais Rurais, existiram também outro tipo de instituição responsável por ensinar pessoas para atuarem nas zonas rurais, caso da Escola de Economia Rural Doméstica, onde as interessadas prestavam os exames vestibulares. Conseguindo aprovação de ingresso, recebiam aulas de diversas disciplinas em regime de internato. A ressaltar que tal processo era totalmente gratuito. Nos distritos de Feira de Santana a prefeitura municipal contratava a professora e a designava para determinada fazenda, onde deveria exercer o magistério.

\section{MATERIAL E MÉTODO OU METODOLOGIA}

A fonte principal utilizada na pesquisa foi o Jornal Folha do Norte, que se encontra arquivado no Museu Casa do Sertão, situado na Universidade Estadual de Feira de Santana. A partir da análise do periódico, encontrei portarias, decretos e matérias que informam sobre as escolas rurais abertas nos distritos de Feira, a contratação e transferência de professoras para estas escolas.

\section{RESULTADOS E/OU DISCUSSÃO}

Durante a pesquisa encontrei dados sobre a abertura de escolas rurais no município de Feira de Santana. Foram tabulados, conforme apresentação a seguir: a quantidade, o local, (geralmente nas fazendas), onde foram instaladas, distrito e nome das escolas rurais. É importante ressaltar que foram expostas algumas das tabelas, pois a sua quantidade perpassa o limite de páginas.

Ano 1956

\begin{tabular}{|c|c|c|c|}
\hline Quantidade & Fazenda & Distrito & Nomenclatura \\
\hline 02 & $\begin{array}{c}\text { Agostinho Duarte e } \\
\text { Boa Vista }\end{array}$ & Jaguara & \\
\hline 03 & $\begin{array}{c}\text { Rio Branco; } \\
\text { Candeal Pequeno e } \\
\text { Lage }\end{array}$ & Pacatú & \\
\hline 01 & Mãe Maria & Ipuassú & \\
\hline
\end{tabular}




\begin{tabular}{|l|c|c|c|}
\hline 01 & Subaé & Humildes & \\
\hline 01 & Riachão & Anguera & \\
\hline
\end{tabular}

Ano 1957

\begin{tabular}{|c|c|c|c|}
\hline Quantidade & Fazenda & Distrito & Nomenclatura \\
\hline 01 & Alecrim Miúdo & Maria Quitéria & $\begin{array}{l}\text { Dr. Antonio } \\
\text { Balbino }\end{array}$ \\
\hline 01 & Guaribas & Anguera & Santos Dumont \\
\hline 02 & $\begin{array}{c}\text { São Bento e Terra } \\
\text { Nova }\end{array}$ & Bonfim de Feira & $\begin{array}{c}\text { Cel. Álvaro Simões } \\
\text { e Des. Filinto } \\
\text { Bastos }\end{array}$ \\
\hline 01 & Boa Vista & Tanquinho & $\begin{array}{c}\text { Dr. Arivaldo Falcão } \\
\text { Pereira }\end{array}$ \\
\hline 01 & Mandacarú & Pacatú & $\begin{array}{l}\text { Dr. Honorato } \\
\text { Bonfim }\end{array}$ \\
\hline 01 & Caatinga & Tiquarussú & $\begin{array}{l}\text { Prof. Antonio } \\
\text { Garcia }\end{array}$ \\
\hline 02 & $\begin{array}{l}\text { Cerâmica Ponte } \\
\text { Grande e Sede }\end{array}$ & Humildes & $\begin{array}{c}\text { Cel. José Pinto dos } \\
\text { Santos e Padre } \\
\text { Henrique Alves }\end{array}$ \\
\hline 01 & Lagoa do Patos & Maria Quitéria & $\begin{array}{c}\text { Prof }^{a} \text {. Estefânia } \\
\text { Mena }\end{array}$ \\
\hline 01 & Chapada & Ipuaçú & \\
\hline 01 & Primavera & Pacatú & \\
\hline
\end{tabular}

\section{CONSIDERAÇÕES FINAIS (ou Conclusão)}

Busquei durante a pesquisa investigar em quais locais foram instaladas escolas rurais e quais as professoras nomeadas para estas. No seu projeto, as escolas primárias das zonas rurais de Feira de Santana tinham como objetivo específico alfabetizar as crianças residentes nas localidades próximas, além de passar ensinamentos de cunho rural, 
considerando ser importante a aprendizagem sobre atividades agrícolas para seus habitantes. Contudo, fiquei limitada por não ter ampliado minha investigação as Atas da Câmara Municipal, o que possibilitaria acesso aos debates sobre sua instalação e dinâmicas de mudanças. Também não busquei ofícios e demais correspondências dos sujeitos da educação, assim como registros dessas escolas, assim como maior ampliação da bibliografia especifica

\section{REFERÊNCIAS}

CARDOSO, Mayra Paniago Spínola. De Normalistas a Professoras: um estudo sobre trajetória profissional feminina em Feira de Santana 1950-1960. Dissertação de Mestrado. Universidade Estadual de Feira de Santana, 2011.

CRUZ, Antonio Roberto Seixas da; RIBEIRO, Marinalva Lopes. Flores do Sertão: Perfilando Professoras Formadas pela Escola Normal de Feira de Santana de 1930 a 1949. Revista HISTEDBR On-line, Campinas, n.36, p. 182-199, dez.2009.

DAMASCENO, Maria Nobre; BESERRA, Bernadete. Estudos sobre educação rural no Brasil: estado da arte e perspectivas. Educação e Pesquisa, São Paulo, v.30, n.1, p. 73-89, jan./abr. 2004.

FONSECA, Henrique de Oliveira. Em defesa da Ruralização do Ensino: Sud Mennucci e o debate político e educacional entre 1920 e 1930. Orientadora: Profa. Dra $^{a}$. Thais Nivia de Lima e Fonseca. Dissertação (Mestrado), Faculdade de Educação da UFMG- Belo Horizonte, 2014.

MENDONÇA, Sônia Regina de. Estado, educação rural e influência norte-america no Brasil (1930-1961). Niterói : Editora da UFF, 2010.

OLIVEIRA, Ana Maria Carvalho dos Santos. Feira de Santana em tempos de Modernidade: Olhares, Imagens e Práticas do Cotidiano 1950-1960. Orientador: Prof. Antonio Paulo de Morais Rezende, Co-orientador Lina Brandão Ares. Tese (Doutorado) Universidade Federal de Pernambuco. 2008.

OLIVEIRA, Clovis Frederico Ramaiana Moraes. "Canções da cidade amanhecente": urbanização, memórias urbanas e silenciamentos em Feira. Orientadora Profa. Dr ${ }^{\mathrm{a}}$. Marcia de Melo Martins. Tese (Doutorado) Universidade de Brasília, 2011.

REZENDE, Cacia Valeria de Rezende. Educação no sertão: memórias e experiências das professoras do alto sertão sergipano (1950-1970). Orientação [de] Profa. Dra. Raylane Andreza Dias Navarro Barreto - Aracaju-Se ; 2013.

SOUSA. Ione Celeste J de. Garotas tricolores, deusas fardadas: as normalistas em Feira de Santa, Bahia-1925/1945. São Paulo: EDUC-PUC/SP; 2001.

VEIGA, Cynthia. Historia política e Historia da educação. In: FONSECA, Thaís Nivia de Lima e; VEIGA, Cynthia Greive. História e Historiografia da Educação no Brasil. - Belo Horizonte: Autentica, 2008. 